\title{
ROSÁRIO FUSCO EM BUSCA DE MARINA, A INTANGÍVEL: HOMENAGEM ZOMBETEIRA A MURILO RUBIÃO
}

Marta Dantas Silva (UEL)

Recebido em 11 ago 2020. Marta Dantas é Mestre em História e Dra. em Aprovado em 04 out 2020. Sociologia pela UNESP; pós-Doutora em Literatura Brasileira pela USP; Professora Adjunta de História e Teorias da Arte do Departamento de Arte Visual e do Programa de Pós-Graduação em Letras da UEL. Autora do livro Arthur Bispo do Rosário: a poética do delírio, São Paulo: Ed.Unesp, 2009.

ORCID iD: https://orcid.org/0000-0003-3877-1284

Resumo: Rosário Fusco (1910-1977) e Murilo Rubião (1916-1991), dois escritores mineiros e que foram contemporâneos. Dois escritores muito diferentes: de um lado, a predileção de Rubião pelo conto, a busca para atingir o essencial, a lentidão na abordagem, os rigores de uma ascese em prol de uma linguagem concisa; do outro, a predileção de Fusco pelo romance ficcional, pelo texto verborrágico e excessivo. Também foram homens bem diferentes, mas com muitos pontos em comum nas suas trajetórias de vida. Além disso, andavam na contramão da tendência dominante da produção literária brasileira dos anos 40; as ficções de Fusco e os contos de Rubião são marcados por acontecimentos insólitos garimpados do cotidiano. A homenagem a Murilo Rubião se faz aqui por meio 
de Rosário Fusco e ao estilo fusquiano. Intento apresentar como a ficção de Fusco, A.S. A. Associação dos solitários anônimos, publicada postumamente em 2003, faz uma séria e zombeteira homenagem ao contista Murilo Rubião.

Palavras-chave: Rosário Fusco; Murilo Rubião; Marina, a intangível; Metaficção.

Abstract: Rosário Fusco (1910-1977) and Murilo Rubião (1916-1991), two writers from Minas Gerais who were contemporaries. Two very different writers: on the one hand, Rubião's predilection for the short story, the search to achieve the essential, the slowness in the approach, the rigors of an asceticism in favor of a concise language; on the other, Fusco's predilection for the fictional novel, for the verbose and excessive text. They were also very different men, but with many points in common in their life trajectories. In addition, both went against the dominant trend of Brazilian literary production in the 1940s; Fusco's fictions and Rubião's short stories are marked by unusual events panned from everyday life. The tribute to Murilo Rubião is done here by means of Rosário Fusco and in the Fusquian style. I intend to present how Fusco fiction, A.S.A. Associação dos solitários anônimos, published posthumously in 2003, makes a serious and mocking tribute to the storyteller Murilo Rubião.

Keywords: Rosário Fusco; Murilo Rubião; Marina, the intangible; metafiction.

\section{GARIMPEIROS DE MISTÉRIOS E ESTRANHEZAS DO COTIDIANO}

Murilo Rubião e Rosário Fusco, dois escritores, duas vidas. Não tenho conhecimento sobre algum tipo de relação, seja ela amigável, intelectual, de admiração ou não, entre estes dois escritores que viveram na mesma época de maneira muito 
diferente, mas que possuem coisas em comum para além do fato de terem sido mineiros e contemporâneos.

Certamente, eram homens bem diferentes. Rosário Fusco era um mulato homenzarrão, nada convencional, que soltava faíscas por onde passava; a mera compra de um par de sapatos virava, com ele, um happening. Segundo Otto Lara Resende (1994, p.122), ele criava em torno de si "turbulenta festa infantil de mentiras coloridas"; precisava da imaginação para viver, "vivia em estado de selvagem liberdade"; era um vulcão ativo. Suas atitudes diante da vida conciliavam o que parecia irreconciliável: "místico terra a terra", "espiritualista-materialista" (WERNECK, 2017, p.80), e, ainda, a "desordem boêmia" com a "conventual disciplina" (RESENDE,1994, p.123). Viveu intensamente. Murilo Rubião parecia ser o oposto. Reservado, solitário, discreto. Suas cartas são repletas de tom melancólico e sentimento de desamparo. A vida social não Ihe parecia muito atraente e, não por acaso, amigos como Otto Lara Resende o chamava de "Alfredo", personagem homônimo do conto "Alfredo", figura melancólica que preferiu passar a vida como um dromedário a conviver com seus semelhantes. Rubião se sentia inapto para a vida: "Verifico, a cada momento, a minha inaptidão para o ofício de viver" (Apud CABRAL, 2016, p.46). Fusco está para a figura do "escritor maldito" assim como Rubião para o do "escritor monástico". Apesar de todas essas diferenças, há muitos pontos em comum nas suas trajetórias de vida.

Rosário Fusco de Souza Guerra (1910-1977) nasceu em São Geraldo, mas cresceu em Cataguases e retornou a ela, depois de viver muitos no Rio de Janeiro, e nela se despediu desta vida. O início de sua aventura literária se confunde com a história do grupo 
e da revista Verde (1927-1929), ambas reconhecidas como um capítulo importante na história do modernismo e das vanguardas no Brasil. Além de poeta, dramaturgo e romancistas, foi crítico literário do Diário de Notícias do Rio de Janeiro, jornalista, radialista, publicitário e advogado. Como funcionário público, atuou como procurador do ex-estado de Guanabara e nos anos 40 foi adido cultural da Embaixada do Brasil em Santiago do Chile.

Murilo Rubião (1916-1991) nasceu em Silvestre Ferraz, mas foi criado em Belo Horizonte, viveu uma temporada no Rio de Janeiro, mas retornou para a capital mineira, que tanto amava, e por lá ficou até a sua morte. Foi contista e escritor incansável. Como Fusco, também foi advogado, jornalista, radialista e funcionário público. Nos anos 50, foi chefe de gabinete de Juscelino Kubitschek, chefe do escritório de Propaganda e Expansão Comercial do Brasil e adido cultural junto à Embaixada do Brasil em Madri. E nos anos 60 foi o responsável pelo Suplemento Literário do Diário Oficial Minas Gerais.

Estes dois homens foram grandes carteadores e se corresponderam com amigos em comum como Mario de Andrade e Otto Lara Resende. Mas não é somente alguns dados biográficos que os aproximam.

À primeira vista, só enxergamos suas diferenças: de um lado, a predileção de Rubião pelo conto, a busca para atingir o essencial, a lentidão na abordagem, os rigores de uma ascese em prol de uma linguagem concisa; do outro, a predileção pelo romance ficcional, pelo texto verborrágico e excessivo.

Na contramão da tendência dominante da produção literária brasileira dos anos 40, as ficções de Fusco e os contos de Rubião 
são marcados por acontecimentos insólitos; a exterioridade e a interioridade se encontram e se confundem em suas obras e, como bons mineiros, garimpavam o cotidiano e dele extraíam mistérios e estranhezas. A presença do insólito nas obras destes mineiros desembocam no trágico. Compartilham da compreensão de que a vida é mais irreal, absurda e concreta do que a fantasia criada pela literatura dita fantástica; para ambos, o cotidiano é o território em que o insólito e o trágico irrompem sem possibilidade de escape e salvação.

A presença de referências bíblicas em suas obras é notável, embora com significados distintos. Nas ficções fusquianas as referências bíblicas estão sempre presentes e em tom de paródia e, muitas vezes, com mensagens invertidas. Em O livro de João (1944) elas não poderiam ser mais explícitas. O livro de João, segunda obra ficcional de Rosário Fusco, publicada em 1944, inicia-se com uma epígrafe: uma passagem do Evangelho de Lucas em que Zacarias afirma que João é o nome de seu filho; mas as referências bíblicas não se limitam a João Batista. Na vida de João, a personagem fusquiana, uma série de eventos insólitos irrompem ao acaso e o desviam do caminho da virtude e do temor a Deus. Sua transfiguração representa a superação desse temor, seu desatino e a reinterpretação de um versículo do apóstolo João - que afirma ninguém ter mais amor do que aquele que sacrifica a vida por seus amigos. João transforma, assim, o assassinato de uma mulher num ato de amor. Fusco, diferente de Rubião, anarquiza a história, os valores e as mensagens bíblicas e cria, por meio delas, analogias invertidas. Rubião faz uso de epígrafes retiradas do texto Bíblico e imagens teofânicas, 
"indizíveis, inefáveis, como são encontráveis em muitas teofanias bíblicas e semitismos" (PERCINO, 2014, p.87). Elas parecem visar o incomunicável, o enigmático da vida e, sobretudo, o enigmático do processo de criação literária, mas elas também podem funcionar como referência intertextual que remete o texto literário ao regime discurso da Bíblia e, as epígrafes, como índice programático para o leitor. Elas foram objeto de investigação de Schwartz (1981), ele as interpreta horizontalmente ao apontar como seus significados se preservam e se disseminam nos contos num jogo intratextual e intertextual, por vezes, numa relação dicotômica (epigrafe/conto). Contudo, como aponta Percino (2014), há outras possibilidades além destas investigadas por Schwartz (1981), pois as epígrafes se dão menos aos percursos retilíneos do que aos das redes plurais de significados. Como as epígrafes abarcam todos os contos, não há dúvidas de que elas fazem parte do projeto artístico-literário de Rubião.

Foram recebidos pela crítica com certa hostilidade e incompreensão. Enquanto Murilo Rubião foi acusado de produzir uma ineficaz fantasia ou, nas palavras de Davi Arrigucci Jr. (1998), de não conseguir "realizar completamente a alquimia transfiguradora do real". Fusco foi acusado de hermetismo, de produzir um mistério vazio e nada original. Em 1943, Mario de Andrade escreveu em uma carta para Rubião suas impressões acerca do conto, que ainda não havia sido publicado, "Marina, a Inatingível":

Eu fico sempre numa enorme dificuldade de dar opinião pra esse gênero de criação em prosa a que estou denominando aqui de baseada no princípio da fantasia. O próprio Kafka, confesso a você que frequentemente me deixa numa 
insatisfação danada [...] meu palpite principal é mesmo esse: os elementos que você utiliza, cria, inventa, na sua fantasia, frequentemente não me convencem, não por serem irreais, mas por não serem suficientemente inesperados. (ANDRADE In: http://www1.folha.uol.com.br/ fsp/1995/2/19/mais!/24.html)

A insatisfação de Mário, explica Mariana Franzin (2014, p.25), deriva da sua necessidade "de manter separadas as categorias da realidade lógica e do insólito" enquanto que, segundo a pesquisadora, a fusão entre estes dois sistemas opostos "é proposital e denota a inovação do autor". Segundo Arrigucci Jr. (1998), Mário de Andrade "nunca aceitou de todo o escritor" Kafka, autor que, nos anos 40, é termo de comparação para muitos críticos diante de produções literárias que surgiam na contramão da tendência em voga no Brasil, o romance social.

No ensaio "Surrealismo no Brasil", publicado em 1945 no livro Brigada ligeira, e outros ensaios, Antônio Candido (1992) dedica ácidos parágrafos ao romance $O$ agressor. $O$ ponto focal da crítica é a transplantação indevida, por parte de Fusco, de modelos europeus e cujo resultado é a artificialidade: seja do clima kafkiano em $O$ agressor, resultando num "mistério pelo mistério"; seja do surrealismo, resultando num "exercício de composição literária", numa "ginástica mental" bem distante da concepção geral do pensamento e da literatura ao qual se originou:

O sr. Rosário Fusco, cuja carreira literária se distingue pela variedade das produções e que tem um lugar de monta na história do modernismo, acaba de publicar o seu primeiro romance, que pode ser classificado de surrealista. [...] O que 
há de fecundo e de permanente nas pesquisas do surrealismo francês, encontramo-lo nos nossos grandes poetas, diluído na realidade mais autônoma de sua poesia. Realidade que não se nutriu apenas de uma dada atitude do espírito, mas de muitas - surrealismo e dadaísmo franceses, expressionismo alemão, imagismo anglo-americano - filtradas e incorporadas à nossa própria realidade espiritual. No livro do sr. Rosário não encontro esse processo de assimilação, mas um mecanismo mais simples de adoção de valores literários, uma tentativa de transplantar a planta estrangeira para a terra pátria. Donde o caráter de exercício, de composição literária que o livro assume. (CANDIDO, 1992, p.105)

A primeira publicação de Rubião, O ex-mágico (1947) e a publicação da primeira ficção de Fusco, O Agressor (1948), tiveram recepção, por parte da crítica, parecidas: as comparações com Kafka, o rótulo ora de surrealista, ora de realismo mágico, entre outras vertentes do insólito ficcional. Ambos negaram ter conhecimento da literatura kafkiana quando escreveram estas obras.

Desde a época da Verde, Fusco manteve uma atitude irônica sobre a questão apropriação $x$ originalidade, porque sempre soou aos seus ouvidos como uma falsa questão. Para ele ideias, pensamentos, palavras, obras parecem não ter proprietário, não são de ninguém: "cada escritor cria os seus precursores, ou, trocando a coisa em miúdos para explicação mais larga: cada um junto é um repetido de todos" (FUSCO Apud FARIA, 2011, p.4) e o que

distingue $o$ artista do comum dos mortais não é, apenas, a capacidade de apreensão do que o mundo lhe oferece, como reservatório de 
símbolos. O que o distingue é o sentimento de transcrição desses símbolos e a [...] capacidade de comunica-los (FUSCO, 1952, p.25).

Rubião, por seu turno, defendia a ideia de que escrever era um ato de recontar histórias já existentes e, para ele, tudo estava gravado nas escrituras sagradas, sua grande fonte de inspiração.

Além disso, verifica-se o lento reconhecimento de suas obras. Todavia, enquanto a obra de Murilo Rubião emerge na superfície da História da Literatura Brasileira, a obra de Rosário Fusco ainda habita suas profundezas.

A homenagem à Murilo Rubião se faz aqui por meio de Rosário Fusco e ao estilo fusquiano. Intento apresentar como ficção de Fusco, A.S.A. associação dos solitários anônimos, publicada postumamente em 2003, estabelece uma relação intertextual com o conto "Marina, a intangível" de Rubião. Sem nenhuma referência exterior a essa ficção de Fusco - que problematiza (entre outras coisas), por meio da ironia, do deboche, do sarcasmo, do grotesco, do insólito, entre outros maneirismos fusquianos, o próprio fazer literário - que confirme esta relação, me arrisco a lê-la como uma séria e zombeteira homenagem ao contista Murilo Rubião.

\section{ROSÁRIO FUSCO EM BUSCA DE MARINA, A INTANGÍVEL}

A.S.A. associação dos solitários anônimos (2003), ficção escrita entre 1966-1967, é um voo ousado. Segundo Fábio Lucas (2003, p.282), "uma narrativa de veloz andamento, polifacetada, palmilhada de contradições, a explorar um recanto especial do cenário brasileiro: a marginalidade acumulada ao longo do cais". Narrativa que esvazia "a realidade de seu conteúdo, faz desfilar, 
por cenários vertiginosamente marginais, seus personagens, sob a égide da lógica do absurdo" (RUFFATO, 2003). Labiríntica e ambígua, seu tempo é "múltiplo e qualitativo, vinculado à duração dos seres" (ANTELO, 2010, p.47).

A "sensibilidade estranhíssima" de Rosário Fusco - uma certa disposição diante da vida, que se confunde com sua opção estética - que se tornou sua marca particular já manifesta na sua primeira ficção, $O$ agressor, foi levada em A.S.A. à exaustão, como bem observou Luiz Ruffato (2003).

O mundo ficcional de A.S.A. publicado, é só complexo e absurdo, mas em Fusco, bem como em Rubião, fantasia inventiva tem nexo pois se trata, também, de uma metaficção. A.S.A. faz alusões, inversões, duplicações de outros textos, de outros autores e gêneros. Sua construção se dá a partir do próprio material ficcional, por meio de relações de composição, recomposição e decomposição de outros textos, inclusive do seu primeiro romance, $O$ agressor. Em outras palavras, nasce de um processo de criação que se apropria de fragmentos de outras fontes "por simples operação de seleção, de levantamento no interior do contínuo do real e de inscrição no universo da arte" (ANTELO, 2010, p.54).

As páginas de A.S.A são divididas em "seções". Elas possuem certa autonomia. A primeira é uma espécie de "introdução", pois apresenta importantes elementos da trama. O narrador inicia a história abruptamente: "De supetão, a vasta sala de pasto foi assaltada por sucessivas levas de feridos, impropérios, choros e blasfêmias" (FUSCO, 2003, p.13). E a voz do narrador continua em tom de mistério: 
Misteriosa solidariedade passou a amalgamar aqueles pobres seres (cabeças apoiadas em ombros, braços carregando corpos) mascarados de sangue. Ninguém se conhecia, e a atmosfera do ônibus desabalado na noite pegando fogo [...] não convidava aos contatos, espontâneos ou procurados, mas à incoercível modorra [...] O que aconteceu, por que aconteceu, ninguém sabia ou soube [...]. (FUSCO, 2003, p.13-14)

O narrador mantém o suspense: “De tudo, apurou-se que, além do motorista, liquidado misteriosamente com uma perfuração na nuca, mais cinco pessoas estavam em carência de extrema-unção" (FUSCO, 2003, p.18). Traz ao leitor a expectativa de um romance policial, que logo é quebrada pelo humor negro: "Nesse momento, a idéia explodiu na bossa religiosa da cabeça do proprietário da pousada, já disposto a acabar com a indústria de comida e dedicarse ao comércio do céu" (FUSCO, 2003, p.18).

Embora a história do acidente não tenha continuidade nas páginas seguintes, mistério, morte, assassinato e culpa são elementos da trama da narrativa e que se desenvolvem na contramão de um romance policial, onde tudo deve ser explicado, desvendado no final. Entre a seção inicial e a final o que temos é uma aventura vertiginosa que precipita o leitor num grande vazio.

Em A.S.A. nada é nítido; tudo e todos "emergem como sombras num mundo enevoado" (FARIA, 2011, p.6). O narrador se comporta como espectador que contempla, a distância e com desinteresse, o mundo exterior, que "extrai um fato ou um conjunto de fatos do que é dado como seu normal, para precipitá-los num jogo vertiginoso de relações inesperadas" (RISTITCH Apud DUPLESSIS, 1963, p.26). 
Muitos personagens não têm nome próprio (Fulana, Sicrana, Beltrano, Perneta, Marujo...); podem ser considerados "qualquer um", e suas histórias surgem como desdobramento da história do protagonista, Fulano.

Fulano é um anti-herói, um sujeito sem atributos, sem qualidades e sem coerência. Ele e outros personagens têm algo em comum: são errantes urbanos guiados pelo acaso e que buscam, na experiência erótica, sua outra metade. Casado há mais de duas décadas com Fulana, sua vida sofre uma reviravolta quando conhece Sicrana.

Num sábado chuvoso, Fulano se encontrou com o amigo Beltrano no bar de um outro amigo, o Alemão. Ingeriram água mineral, limonada e trataram dos documentos para a futura fundação da A.S.A. Depois, caminharam juntos até o ponto de ônibus, se despediram e, então, Fulano foi tomado por uma "sensação de inédita liberdade" (FUSCO, 2003, p.23). Consultavase: o que estava acontecendo? Fora impelido a mudar de rota, seguir um outro caminho que não o habitual, o de casa, mas em direção ao mercado do cais do porto.

No mercado do cais, Fulano sentou-se para beber e petiscar e "interessou-se por uma mulata de prendas adolescentes, transfigurado noutro homem, convidou-a a dormir com ele: sem rodeios" (FUSCO, 2003, p.26). Ele se apresentou à moça, chamada de Sicrana, como Basilisco; o que indica sua transfiguração, mas também seu anonimato. Embriagado, o casal se dirigiu para o quarto de um dos cortiços do cais. Fulano estava muito bêbado e o que era esperado não aconteceu. 
Desse dia em diante, Sicrana se tornou seu objeto de desejo e Fulano passou a experimentar seus desejos eróticos por ela em seu sonhos e devaneios. O protagonista que se encontra diante de um conflito, ou melhor, de uma descoberta: seu corpo, até antão vazio de desejo, é despertado pelo desejo de ser um outro, Basilisco, desejoso de uma mulher, Sicrana. Fulano transfere para ela o amor que sentia pela sua filha prematuramente morta, Marina.

As práticas eróticas são insinuadas e cabe ao leitor dar vida a elas por meio da sua imaginação. O erotismo fusquiano se aproxima, portanto, da busca pela obra de arte ou literária ideal e intangível; e o interesse pelo desvio da norma sexual é, em A.S.A., uma metáfora do desvio das normas literárias e da gramática usual. E a errância das personagens, em busca de outros corpos que as completem, é análoga a do leitor em busca de preencher as lacunas do texto e o vazio das palavras, busca que não se finda, que nunca alcança a satisfação.

A.S.A não é uma ficção erótica, mas é fruto do que Raúl Antelo (2013, p.21) chama de "prática erótica da linguagem", porque escritura e erotismo caminham de mãos dadas, ambos advém da perda, do dispêndio improdutivo do tempo num algo inútil, o que faz dela "luxo da linguagem", linguagem inútil, vazia. É o gozo na experiência supérflua da escrita.

No entanto, é essa nulidade que

constitui talvez uma força extraordinária, maravilhosa [...] Fazer com que a literatura se torne a revelação desse dentro vazio, que inteira se abra à sua parte de nada, que realize sua própria irrealidade [...] é correto atribuirIhe a maior ambição criadora, pois, assim que a 
literatura coincide por um instante com nada, imediatamente ela é tudo (BLANCHOT, 1997, p. 292)

Nesse jogo de duplos, Fulano/Basilisco, Sicrana/Marina, é a voz de Rosário Fusco que ecoa nas falas das personagens de A.S.A., como observou Daniel Faria (2011, p.6):

Se num romance, por seu estatuto polifônico, os personagens são desenhados como diferentes perspectivas existências, éticas, sobre o mundo encenado, expressas por diferentes idiomas, estilos, atitudes discursivas, a polifonia de Rosário Fusco é estranhamente monocórdia. O narrador e todos os personagens adotam o mesmo tom discursivo: a fala alusiva, elíptica, evasiva expressão de uma atitude filosófica entre cética e cínica. [...] Ou seja: todos são distintos, porém falam a mesma língua, a do autor Rosário Fusco.

Em nenhuma das ficções anteriores a A.S.A encontramos a presença tão marcante de Rosário Fusco. E entre todas as personagens, é Fulano, certamente, o mais próximo do autor porque é a personificação do devir a ser poeta, artista, anônimo. É também o duplo do escritor, porque a força do desejo que o impele à busca de si mesmo e de Sicrana/Marina, exige o sacrifício da sua vida ordinária. O seu tempo é consumido na errância, no esquecimento de si e nos sonhos eróticos; uma vida tal e qual a obra literária exige do seu autor (BLANCHOT, 1987). E Marina/ Sicrana é, a um só tempo, a musa que inspira e desorienta, a obra almejada e fugidia; relação que equivale ao erotismo em A.S.A.

Entretanto, uma outra Marina antecedeu a de Rosário Fusco. Em 1947 Murilo Rubião publicou o conto "Marina, a Intangível" (2010). Não posso evitar ver na Marina de Fusco um parentesco com a Marina de Rubião. 
"Marina, a Intangível" conta a história de um jornalista, José Ambrósio, que trabalha durante a noite na redação do jornal, mas que se vê tomado pela impossibilidade de cumprir com sua tarefa: escrever. Desesperado, fez uma oração para "Marina, a Intangível". A oração ajudou-o "a reprimir a angústia", mas não - "libertou da incapacidade de cumprir as tarefas noturnas" (RUBIÃO, 2010, p.103). Abriu a bíblia e depois de ter lido algumas páginas descobriu o assunto procurado: falar do mistério de Marina, a Intangível, também conhecida por Marina da Conceição, pois mudou de nome ao fugir com o namorado. Mas a alegria durou pouco, assim que ia botar no papel a primeira frase, a mesma fugia da pena de José Ambrósio. A situação se torna mais crítica com o aparecimento de um estranho reflexo no vidro, o duplo que, num primeiro momento, o protagonista não reconhece. E à semelhança do que ocorre em Fausto, de Goethe, o duplo ganha corpo e propõe um pacto: "- Recebi o seu recado, José Ambrósio. Aqui estou. [...] São versos para publicar. Os que você me encomendou." (RUBIÃO, 2010, p.105-106). José Ambrósio, tomado pela ira grita: "- Morra a poesia, morram os poetas!", e cai de joelhos quando seu duplo explica: "-São versos para Marina, a Intangível" (RUBIÃO, 2010, p.106).

José Ambrósio e seu duplo trabalham juntos na publicação dos tais versos dedicados à Marina mesmo sem possuírem os meios para tanto; mas os versos, segundo o duplo, "prescindem de máquinas" (RUBIÃO, 2010, p.108). De posse das rosas que havia exigido, o duplo se põe a desfolha-las. "Rasgou as pétalas, pela metade, e colocou-as no chão. Formou palavras" que Ambrósio não soube decifrar, mas que foram assim explicadas pelo duplo: 
“- Os primeiros cantos são feitos de rosas despetaladas. Lembram o paraíso antes do pecado" (RUBIÃO, 2010, p.108), enquanto que os últimos cantos inexistem.

O conto termina com uma espécie de procissão onde Marina, a Intangível, aparece "escoltada por padres sardentos e mulheres grávidas [...] Os lábios, excessivamente pintados" e um vestido rasgado que deixava entrever "suas coxas brancas, bem feitas" (RUBIÃO, 2010, p.109). Na procissão, Marina tomava o lugar da Virgem. José Ambrósio quis correr para alcançar o andor, porém os papéis jogados para o ar o impediram e quando se desvencilhou dos mesmos, encontrou-se só "no terreiro e nenhum som, nenhum ruído se fazia ouvir. Sabia, contudo, que o poema de Marina estava composto, irremediavelmente composto. Feito de pétalas rasgadas e de sons estúpidos" (RUBIÃO, 2010, p.110).

Na interpretação de Franzim (2015, p.52), Marina é a musa fantasmática cuja imagem transtorna a mente de José Ambrósio e, "quanto mais próxima ela parece estar mais intangível se torna". Marina encarna a "forma poética tão desejada", "a própria escrita" e Franzim (2015, p.52) considera "o inquietante duplo e a fantasmática Marina" como "faces do fazer poético".

José Ambrósio, ele mesmo uma espécie de duplo de Rubião, é um poeta que luta pelo intangível; o intangível é justamente o que o poeta deve captar para ser poeta, mas o preço é justamente a morte do autor que, no caso de José Ambrósio se manifesta no seu desdobramento, na sua fragmentação, ou seja, na sua autodestruição.

Podemos dizer que sua questão chave é a experiência da escrita como "experiência limite" (BLANCHOT, 1987). "Experiência" 
porque coloca o autor em contato com o ser, e "limite" porque desencadeia a renovação do Eu nesse contato, colocando-o em crise. Não há dúvidas que se trata, entre outras coisas, de um conto metalinguístico e que reconhecemos na angústia de José Ambrósio aquela de Rubião.

Destarte, podemos dizer que a experiência assustadora e desnorteante de Ambrósio, antes e diante da aparição de Marina, e a errância de Fulano em busca de Sicrana/Marina, são análogas. São metáforas (alegorias?) da experiência literária uma vez que "escrever é descobrir o interminável", como explica Blanchot (1987, p.18); é embarcar em uma aventura em que nada garante "um mundo mais seguro, mais belo, mais justificado, onde tudo se ordenaria segundo a claridade de um dia justo" (BLANCHOT, 1987, p.18).

A Marina de Fusco é "Marina, a Intangível", musa que inspira, mulher fantasmática, portadora da morte e a obra almejada, fugidia, intangível; imagem da linguagem que o escritor quer se ver expresso nela, mas que, todavia, não passa de uma imagem, de uma linguagem vazia, sem espessura.

Vale lembrar que a aventura de Fulano não é a aventura do homem Fusco, assim como a de Ambrósio não é a do homem Rubião. Escrever "não é contar as próprias lembranças, suas viagens, seus amores e lutos, sonhos e fantasmas" (DELEUZE, 1997, p.12), também "não é certamente impor uma forma (de expressão) a uma matéria vivida" (DELEUZE, 1997, p.11). Tampouco é a expressão das neuroses do autor. A literatura segue uma outra via, numa outra direção. Ela só se instala descobrindo sob a pessoa do autor a potência do impessoal, do informe e do 
inacabado. Daí decorre o sentimento ambíguo, de Rubião e de Fusco, diante da literatura.

Murilo afirmou: "Sim, a literatura não cura é paliativo. Contudo, a ela devo não me ter suicidado quando perdi a Fé, escapado ao hospício [...]. Sei que ela me conduzirá a Deus, já que me reconduziu ao Mistério" (Apud CABRAL, 2016, p.56).

Fusco expressou o mesmo sentimento ambíguo da seguinte forma:

Tenho perdido ônibus, bondes, empregos, amizades. Nunca perdi a vontade de escrever... Não sei, em verdade, porque escrevo, se todos escrevem, se há tantas coisas na vida menos melancólicas e mais eficientes...Vivo [...] sob o signo do imprevisto [...] Vivo num mundo onde poucos penetram [...] Escrever é um mal, um bem, é um erro? É tudo isso e não é nada disso: é uma fatalidade. (Apud WERNECK, 2017, p.45)

O devir engendrado pela escrita avizinha aquele que escreve da zona da indiscernibilidade ou de indiferenciação. A aventura de Fulano é essa, a do devir a ser, devir a ser Basilisco, fantasma, solitário e, sobretudo, anônimo. Aventura análoga a de Fusco no processo de escrita de A.S.A.; escrita que, paradoxalmente, faz ecoar a voz de Fusco, mas este também lançou-o no devir a ser outros, entre eles, Ambrósio/Rubião. Como numa sessão espírita, A.S.A. recebe muitas entidades do universo ficcional; mas não se trata de metafísica, se trata de metaficção. É confuso, mas a "confusão sempre foi geral". "E ai de nós se a existência não fosse confusa, fusa, fusional, fissível, fusca, fusco. Amém" (FUSCO, 1976, p.11). E assim, Fusco faz homenagem, zombeteira, a Marina de Rubião e ao fazer literário. 


\section{REFERÊNCIAS}

ANDRADE, Mario ([1943] 1995). Mario escreve a Rubião. São Paulo, 27 dez. In: https://www1.folha.uol.com.br/fsp/1995/2/19/mais!/24.html

ANTELO, Raúl (2010). "Anarquismo, anartismo". In: . Maria com Marcel:

Duchamp nos trópicos. Belo Horizonte: Ed. UFMG, p.29-79.

(2013). "Prefácio: o lugar do erotismo". In: BATAILLE, Georges. O erotismo. Fernando Scheibe (Trad.). Belo Horizonte: Autêntica, p.19-24.

ARRIGUCCI Jr., Davi (1998). "O sequestro da surpresa". Jornal de resenhas Folha de São Paulo, 11 de abril. In http://www.murilorubiao.com.br/criticas. aspx?id=10 Acesso em: 13.Set.2014.

BLANCHOT, Maurice (1987). O espaço literário. Álvaro Cabral (Trad.). Rio de Janeiro: Rocco.

(1997). "A literatura e o direito à morte". In: A parte do fogo.

Ana Maria Scherer (Trad.). Rio de Janeiro: Rocco, p.289-330.

CABRAL, Cleber Araújo (2016). Mares interiores: correspondências de Murilo Rubião \& Otto Lara Resende. Belo Horizonte: Autêntica Editora: Editora UFMG. CANDIDO, Antonio (1992). "Surrealismo no Brasil". In: Brigada ligeira e outros escritos. São Paulo: Ed. UNESP, p.103-107.

DELEUZE, Gilles (1997). "A literatura e a vida". In: Crítica e clínica. Peter Pál Pelbart (Trad.). São Paulo: Edi. 34, p.11-17.

DUPLESSIS, Yves (1963). O surrealismo. 2.ed. São Paulo: Difusão Européia do Livro.

FARIA, Daniel (2011). "Uma história em tempos dilacerados: a vida acidentada de Rosário Fusco". Fênix - Revista de História e Estudos Culturais, Brasília, v. 8, n. 2, mai-ago. 21p. In http://www.revistafenix.pro.br/artigos26.php Acesso em: 12.Mar.2020.

FRANZIM, Mariana Silva (2015). O caráter insólito da escrita rubiana: diálogos a partir de "Marina, a Intangível". Dissertação. 135f. (Mestrado em Letras) Universidade Estadual de Londrina, Londrina.

FUSCO, Rosário (1952). "Criação e criador". In: Introdução à experiência estética. Rio de Janeiro: Departamento de Imprensa Nacional, p.23-36. 
(1976). "Rosário Fusco: o escritor brasileiro é um supercamelô". Pasquim, Rio de Janeiro, 7(351), 10-14, [Entrevista concedida a Ronaldo Werneck e Joaquim Branco]. (2003). A.S.A. Associação dos solitários anônimos. Cotia: Ateliê Editorial. LUCAS, Fábio (2003). "Posfácio: a volta de Rosário Fusco". In: FUSCO, Rosário. A.S.A. - associação dos solitários anônimos. Cotia/São Paulo: Ateliê Editorial, p.277-282 [LêProsa].

PERCINO, E. B (2014). Murilo Rubião: senso e não senso. São Carlos: EduFSCar. RESENDE, Otto Lara (1994). "Rosário Fusco Poeira sonâmbula”. In: O príncipe e o sabiá e outros perfis. São Paulo: Companhia das Letras: Instituto Moreira Salles, p.117-124.

RUBIÃO, Murilo (2010). "Marina, a Intangível". In: Obra completa. São Paulo: Companhia das Letras, p.103-110.

RUFFATO, Luiz (2003). “Rosário Fusco (1910-1977)”. In: FUSCO, Rosário. A.S.A. associação dos solitários anônimos. Cotia/SP: Ateliê Editorial. [Texto da orelha do livro]

SCHWARTZ, J (1981). Murilo Rubião: a poética do uroboro. São Paulo: Ática. WERNECK, Ronaldo (2017). Sob o signo do imprevisto. Cataguases: Poemação produções. 